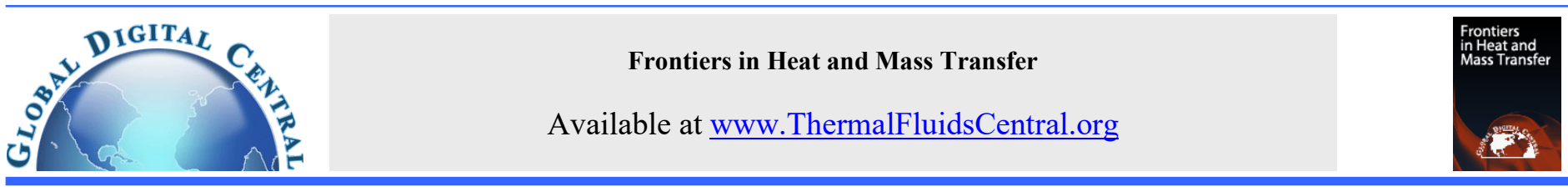

\title{
EFFECTS OF SERRATED PULSATING AIRFLOW ON LIQUID FILM EVAPORATION IN A VERTICAL CHANNEL: A NUMERICAL STUDY
}

\author{
Changming Ling a,b,* Yin Zhonga,b \\ ${ }^{a}$ Shenzhen Institute of Guangdong Ocean University, Shenzhen 518120, China \\ ${ }^{b}$ School of Mechanical and Power Engineering, Guangdong Ocean University, Zhanjiang, Guangdong Province, 524000, China
}

\begin{abstract}
Effects of serrated pulsating airflow on liquid film evaporation in a falling film channel was numerically studied based on a two-dimensional model. The mechanism of pulsating airflow evaporation was studied as the pulsating airflow swept across the vertical liquid film surface at the stagnant temperature. Effects of amplitude, frequency, and velocity of the serrated pulsating airflow at certain evaporation time on evaporation were analyzed. Compared with the uniform airflow, the highest relative evaporation of liquid film on vertical pipe inner surface was increased by about $0.3 \%$. When the airflow was pulsating, the cycle of vapor mass flow rate was the same as the cycle of pulsating airflow. Pulsating airflow disturbed the boundary layer periodically and carried the vapor away; this intensified the mass transfer of liquid film, hence promoting vapor generation under certain conditions.
\end{abstract}

Keywords: numerical simulation; serrated pulsating airflow; water evaporation; liquid film surface

\section{INTRODUCTION}

The rapidly increasing demand for fresh water is triggering severe water crisis globally. The global water storage is about 1.386 billion cubic kilometers, and only account for $0.2 \%$ of global water storage is available. Eighty countries and regions with a population of about 1.5 billion lack fresh water, and about 300 million of them fall in to the trap of water shortage. It is estimated that 3 billion people in the world will face water shortage in 2025 , and 40 countries will be seriously deficient in fresh water (Gao and Ruan, 2015). With the increasing problems of water resource reduction and water pollution, the water crisis has become the world's second environmental issue after the global warming. Desalination is an inevitable choice to solve the water crisis and develop new safe water sources (Wang and Zhou et al., 2003). Multi-effect evaporation, multi-stage flashing, vapor compression distillation, solar distillation, crystallization, electrodialysis and reverse osmosis methods are the techniques of desalinations (Choi and Yoon, 2019). Some new technologies for seawater desalination have been developed to facilitate water evaporation (Xie and Li et al, 2019).

Pulsating flows occurred in various technical systems and engineering applications (Srivastava and Dhiman, 2019; Zhai and Wang et al, 2015; Huang and Yang et al, 2010). Piston pumps, compressors, resonance tube vibrations, flow control valves, flow separation phenomena behind obstacles in pipelines, and some multiphase flow conditions present in the industry generally promote the occurrence of pulsating and other dynamic changes in fluid flow parameters. Pulsating can find its applications in many industries, such as energy, automotive, chemical, pharmaceutical, and food industry (Douglas and Gasiorek et al, 1995). Many studies about the use of pulsating energy have been carried out.

Goltsman and Saushin (2019) designed a pulsator based on the different frequencies to obtain a continuous pulsating flow that could provide sinusoidal fluctuations in a channel. Kærn and Markussen et al
(2018) compared the liquid mass flow and vapor quality of the pulsating and non-pulsating flow in a tube with different periods through the experiments of uniform and pulsating boiling in the tube. They concluded that pulsating flow evaporation efficiency was higher than that without pulsating evaporation in a certain period. Teng and Lim et al (2018) investigated heat transfer from an immersed tube in a pulsating fluidized bed and obtained the effects of immersed tube's temperature, pulsating frequency, inlet superficial velocity and pulsating amplitude on heat transfer behaviors; they observed the best heat transfer performance at high pulsating frequency. Yang and Zhang et al (2018) studied a two-phase pulsating flow in the evaporator. By measuring the heat transfer coefficient of pulsating two-phase flow of R134a in an evaporation channel, it was concluded that the convective heat transfer efficiency of pulsating airflow was higher than that of the non-pulsating airflow in a certain period.

Zhai and Dong et al (2009) simulated the turbulent pulsating flow and heat transfer using the standard $k-\varepsilon$ model combined with the experimental parameters of pulsating burner tailpipe, and established a turbulent flow calculation model that was suitable for the pulsating flow under experimental conditions. They found that pulsating had effects on heat transfer coefficient and friction coefficient by studying the effects of pressure, amplitude and frequency on turbulent flow and heat transfer characteristics in turbulent flow. Li and Guo et al (2019) investigated the slot-jet impingement and revealed that triangular wave could achieve high-efficient heat transfer enhancement. Leonard and Lim et al (2019) experimentally studied the mixing and segregation behaviors of a binary mixture in a pulsating fluidized bed by applying a square-wave pulsating flow. The result showed that magnitudes of particle velocity were high at large pulsating amplitudes or high pulsating frequencies. Wu and Wang (2007) researched the turbulent pulsating flow and heat transfer in an internally longitudinal protuberant finned tube. They found that the intensity of heat transfer enhancement increased with increase of pulsating frequency, while the pressure drop was simultaneously increased. The intensification of heat transfer in

\footnotetext{
* Corresponding Author. Email: ling-cm@163.com
} 
internally longitudinal protuberant finned tube was more significant than the pressure drop with increase of pulsating frequency.

In terms of enhanced heat transfer, the pulsating working medium can intensify the perturbance to the boundary layer, thereby enhancing the convective heat transfer between the fluids (Li and Xiang et al, 2012; Feng and Guo et al, 1998). It was found that the water evaporation rate increased by 1.5 times if the airflow was pulsating compared with the uniform airflow at the certain condition (Liu, 2001). Based on these studies, the perturbance had a certain effect on evaporation. By utilizing the perturbance, the higher the evaporation efficiency. Authors (Zhong and Ling et al, 2020) established a two-dimensional physical and mathematical model of vertical plate falling film evaporation, and studied the effects of pulsating airflow on falling film evaporation process at vertical plate. We found compared with uniform airflow, the pulsating airflow can effectively enhance the convective mass transfer of falling film evaporation. So we use the same idea and method research the effects of serrated pulsating airflow on falling film evaporation process on the inner surface of the vertical round channel.

The objective of this work is to study evaporation of a vertical liquid film surface perturbed by serrated pulsating airflow to enhance the water evaporation. To analyze the effects of the flow parameters of serrated pulsating airflow on evaporation, water evaporation as the pulsating airflow sweeping through the vertical water surface at stagnation temperature will be studied. Effects of amplitude, frequency and airflow velocity of serrated pulsating airflow on the water evaporation will be investigated.

\section{THEORETICAL MODEL}

\subsection{Physical model}

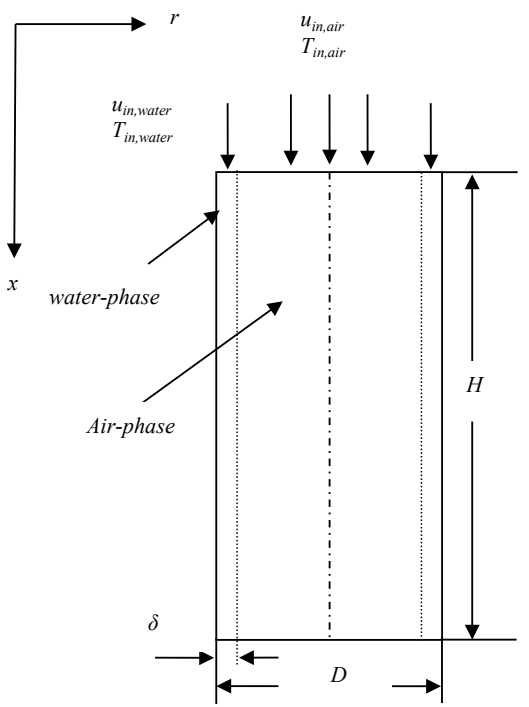

Fig. 1 Physical model

Fig.1 shows a simplified two-dimensional model of a serrated pulsating airflow sweeping through the liquid film in a falling film channel. The water forms a liquid film flowing downward on the inner surface of the channel. The pulsating airflow enters into the top of the channel, sweeping through the liquid film surface for heat exchange, and carries the vapor away from the bottom of the channel. The geometry parameters in the physical model are set as $H=0.5 \mathrm{~m}, D=0.05 \mathrm{~m}$, and $\delta=$ $0.002 \mathrm{~m}$.

\subsection{Mathematical models}

\subsubsection{Governing equations}

Volume of fluid (VOF) model can simulate two or more non-mixed fluids, and it is more suitable for simulations with large variations in gas-liquid interface (Gao and Morley et al, 2003; Vivekanand and Raju1 2019; Kihara. and Obata et al, 2019). Comparing with the standard $k-\varepsilon$ model, the RNG $k-\varepsilon$ model is derived from the instantaneous Navier-Stokes equations. It can handle high strain rate and streamline bending flow, capturing turbulent diffusion at multiple scales which is suitable to model flow near the wall and is more reliable than the standard $k-\varepsilon$ model (Chen, 2018; Han and Wang et al, 2010; Yakhot and Orszag, 1986). This work solves the two-dimensional unsteady incompressible flow and heat transfer through RNG $k-\varepsilon$ model and VOF multi-phases method. The governing equations are as follows. The rates of evaporation condensation are given by (Lee, 1980):

$$
\begin{gathered}
m_{\mathrm{v}}=-m_{\mathrm{w}}=r \alpha_{\mathrm{w}} \rho_{\mathrm{w}} \frac{T-T_{\mathrm{s}}}{T_{\mathrm{s}}} \quad, T>T_{\mathrm{s}} \\
m_{\mathrm{w}}=-m_{\mathrm{v}}=r \alpha_{\mathrm{v}} \rho_{v} \frac{T_{\mathrm{s}}-T}{T_{\mathrm{s}}} \quad, T<T_{\mathrm{s}}
\end{gathered}
$$

where $m_{\mathrm{v}}$ and $m_{\mathrm{w}}$ are the phase-transition rate of vapor and water, respectively, $r$ is the evaporation-condensation coefficient $(r=0.1), \alpha_{v}$ and $\alpha_{\mathrm{w}}$ are the volume fraction of vapor and water, respectively, $\rho_{\mathrm{v}}$ and $\rho_{\mathrm{w}}$ are the density of vapor and water, respectively, $T$ is the system temperature, and $T_{\mathrm{s}}$ is the saturation temperature.

Continuity equation of water film is as following (Tao, 1988):

$$
\frac{\partial u_{\mathrm{w}}}{\partial x}+\frac{\partial v_{\mathrm{w}}}{\partial r}=0
$$

where $u_{\mathrm{w}}$ is axial velocity, $v_{\mathrm{w}}$ is radial velocity of the water film. Momentum equation of water film is:

$$
\rho_{\mathrm{w}}\left(u_{\mathrm{w}} \frac{\partial u_{\mathrm{w}}}{\partial \mathrm{x}}+v_{\mathrm{w}} \frac{\partial v_{\mathrm{w}}}{\partial r}\right)=-\frac{\partial p_{\mathrm{w}}}{\partial r}+\eta_{\mathrm{w}} \frac{1}{\partial x}\left(\frac{\partial u_{\mathrm{w}}}{\partial x}\right)+\rho_{\mathrm{w}} g
$$

where $\eta_{\mathrm{w}}$ is the dynamic viscosity and $g$ is gravitational acceleration. Energy equation of water film is given by:

$$
\frac{\partial}{\partial x}\left(\rho_{\mathrm{w}} C_{\mathrm{p}, \mathrm{w}} u_{\mathrm{w}} T_{\mathrm{w}}\right)+\frac{\partial}{\partial r}\left(\rho_{\mathrm{w}} C_{\mathrm{p}, \mathrm{w}} u_{\mathrm{w}} T_{\mathrm{w}}\right)=\frac{\partial}{\partial r}\left(\lambda_{\mathrm{w}} \frac{\partial T_{\mathrm{w}}}{\partial r}\right)
$$

where $C_{\mathrm{p}, \mathrm{w}}$ is specific heat, $\lambda_{\mathrm{w}}$ is thermal conductivity, and $T_{\mathrm{w}}$ is temperature of water film.

Continuity equation of mixture film (vapor and air) is as following:

$$
\frac{\partial u_{\mathrm{g}}}{\partial \mathrm{x}}+\frac{\partial v_{\mathrm{g}}}{\partial r}=0
$$

Momentum equation of mixture film is:

$$
\rho_{\mathrm{g}}\left(u_{\mathrm{g}} \frac{\partial u_{\mathrm{g}}}{\partial \mathrm{x}}+v_{\mathrm{g}} \frac{\partial v_{\mathrm{w}}}{\partial r}\right)=-\frac{\partial p_{\mathrm{g}}}{\partial r}+\eta_{\mathrm{g}} \frac{1}{\partial x}\left(\frac{\partial u_{\mathrm{g}}}{\partial x}\right)+\left(\rho_{\mathrm{g}}-\rho_{0}\right) g
$$

where $\rho_{0}$ is inlet density.

Energy equation of mixture film is given by:

$$
\frac{\partial}{\partial x}\left(\rho_{\mathrm{g}} C_{\mathrm{p}, \mathrm{g}} u_{\mathrm{g}} T_{\mathrm{g}}\right)+\frac{\partial}{\partial r}\left(\rho_{\mathrm{g}} C_{\mathrm{p}, \mathrm{g}} u_{\mathrm{g}} T_{\mathrm{g}}\right)=\frac{\partial}{\partial r}\left(\lambda_{\mathrm{g}} \frac{\partial T_{\mathrm{g}}}{\partial r}\right)+\frac{\partial}{\partial r}\left[\rho_{\mathrm{g}} D\left(C_{\mathrm{p}, \mathrm{v}}-C_{\mathrm{p}, \mathrm{a}}\right) \frac{\partial w}{\partial r}\right]
$$

Species diffusion equation is:

$$
\rho_{\mathrm{g}}\left(u_{\mathrm{g}} \frac{\partial w}{\partial x}+v_{\mathrm{g}} \frac{\partial w}{\partial r}\right)=\frac{\partial}{\partial r}\left(\rho_{\mathrm{g}} D \frac{\partial w}{\partial r}\right)
$$

Turbulent dissipation rate $\varepsilon$ transport equation is described as:

$$
\rho u_{\mathrm{g}} \frac{\partial \varepsilon}{\partial x}+\rho v_{\mathrm{g}} \frac{\partial \varepsilon}{\partial r}=\frac{\partial}{\partial r}\left[\left(\eta+\frac{\eta_{\mathrm{t}}}{\sigma_{\varepsilon}}\right) \frac{\partial \varepsilon}{\partial r}\right]+C_{1} \frac{\varepsilon}{k} \eta_{\mathrm{t}} \frac{\partial u_{\mathrm{g}}}{\partial x}\left(\frac{\partial u_{\mathrm{g}}}{\partial x}+\frac{\partial v_{\mathrm{g}}}{\partial r}\right)-C_{2} \rho \frac{\varepsilon^{2}}{k}
$$

Kinetic energy $k$ transport equation is written as:

$$
\rho u_{\mathrm{g}} \frac{\partial k}{\partial x}+\rho v_{\mathrm{g}} \frac{\partial k}{\partial r}=\frac{\partial}{\partial r}\left[\left(\eta+\frac{\eta_{\mathrm{t}}}{\sigma_{\mathrm{k}}}\right) \frac{\partial k}{\partial r}\right]+\eta_{\mathrm{t}} \frac{\partial u_{\mathrm{g}}}{\partial x}\left(\frac{\partial u_{\mathrm{g}}}{\partial x}+\frac{\partial v_{\mathrm{g}}}{\partial r}\right)-\rho \varepsilon
$$

where $\eta_{\mathrm{t}}$ is the turbulence coefficient of viscosity, $\eta_{\mathrm{t}}=\rho C_{\mu} k^{2} / \varepsilon$, and $C_{\mu}$ is the viscosity constant. $C_{1}=1.42-\left[\tilde{\eta}(1-\tilde{\eta} / \eta 0) /\left(1+\beta \tilde{\eta}^{3}\right], \tilde{\eta}=S k / \varepsilon, S=\left(2 S_{\mathrm{i}, \mathrm{j}} S_{\mathrm{i}, \mathrm{j}}\right)^{1 / 2}\right.$, $\eta_{0}=4.38, \beta=0.015, S_{\mathrm{i}, \mathrm{j}}=\left(\partial u_{\mathrm{i}} / \partial x_{\mathrm{j}}+\partial u_{\mathrm{i}} / \partial x_{\mathrm{i}}\right) / 2, C_{2}=1.68, \sigma_{\varepsilon}=1.3$, and $C_{\mu}=0.0845$, $\sigma_{\varepsilon}=0.7179$. 
The principle of mixing derives material attribute equation is (Feddaoui, 2003):

$$
\rho=\alpha_{\mathrm{a}} \rho_{\mathrm{a}}+\alpha_{\mathrm{w}} \rho_{\mathrm{w}}+\alpha_{\mathrm{v}} \rho_{\mathrm{v}}, \eta=\alpha_{\mathrm{a}} \eta_{\mathrm{a}}+\alpha_{\mathrm{w}} \eta_{\mathrm{w}}+\alpha_{\mathrm{v}} \eta_{\mathrm{v}}
$$

where $\alpha$ is the volume fraction.

\subsubsection{Boundary conditions}

(1) Inlet boundary: entrance is set to be velocity-inlet.

$$
\begin{gathered}
u_{\text {in,air }}=\left\{\begin{array}{l}
\frac{4 A_{0}}{t_{0}} t-(4 n+1) A_{0}+u_{0}, n t_{0} \leq t \leq(2 n+1) \frac{t_{0}}{2} \\
-\frac{4 A_{0}}{t_{0}} t+(4 n-1) A_{0}+u_{0},(2 n+1) \frac{t_{0}}{2} \leq t \leq(n+1) t_{0}
\end{array}\right. \\
T_{\text {in,air }}=\text { const }, u_{\text {in,water }}=\text { const }, \quad T_{\text {in,water }}=\text { const }
\end{gathered}
$$

where $u_{0}$ is the mean velocity of pulsating airflow of air, $A_{0}$ is the inlet airflow pulsating amplitude of air, $u_{\text {in,water }}$ is the inlet velocity of water,

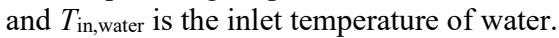

(2) Wall boundary condition: the wall is set to be no slip solid boundary, and the wall temperature is at the saturation temperature.

(3) Outlet boundary: exit is set to pressure-outlet, and the pressure is atmospheric pressure.

\subsubsection{Parameter definition}

Sherwood number is an infinite number reflecting the mass transfer phenomenon:

$$
S h=\frac{h_{\mathrm{m}} d}{K_{\mathrm{z}}}
$$

where $K_{\mathrm{z}}$ is diffusion mass transfer coefficient of vapor in air, the equation is as follows:

$$
K_{\mathrm{z}}=K_{0}\left(\frac{T_{\text {in,air }}}{T_{0}}\right)^{1.5} \frac{p_{0}}{p}
$$

where $K_{0}$ is the characteristic coefficient of vapor in the air. $K_{0}=2.55 \times 10^{-5} \mathrm{~m}^{2} \cdot \mathrm{s}^{-1}, \quad T_{0}=298 \mathrm{~K}$.

$h_{\mathrm{m}}$ is mass transfer coefficient of vapor in air:

$$
h_{\mathrm{m}}=\frac{m_{1}}{\rho_{\mathrm{v}}\left(1-c_{1}\right)}
$$

where $m_{1}$ is the mass transfer flux, $\mathrm{kg} \cdot \mathrm{m}^{-2} \cdot \mathrm{s}^{-1} ; c_{1}$ is the relative humidity of the outlet.

The average Sherwood number:

$$
S h_{\mathrm{pj}}=\int \frac{S h}{\tau} d \tau
$$

The Womersley number is a dimensionless number of frequencies:

$$
W_{o}=d \sqrt{2 \pi f / \eta}
$$

where $f$ is frequency of pulsating airflow, $\mathrm{Hz} ; \eta$ is fluid dynamic viscosity, $\mathrm{kg} \cdot \mathrm{m}^{-1} \cdot \mathrm{s}^{-1}$.

Relative pulsating amplitude of air:

$$
A=\frac{A_{0}}{u_{0}}
$$

The dimensionless time:

$$
\tau=\frac{t}{t_{0}}
$$

\section{SOLUTION METHOD}

\subsection{Design of numerical simulation}

Commercial software ANSYS FLUENT 15.0 is adopted to this numerical simulation. Since the flow is in the axisymmetric, the problem can be simplified to a two-dimensional problem. Twodimensional half-sectional model rotates around the axis for a complete round channel by using axisymmetric swirl function.
In the simulation, the implicit VOF multi-phases model, energy equation and RNG $k-\varepsilon$ turbulence model are activated, and standard wall functions are adopted. The phase change evaporation equation is used in the study, setting air as the first phase, water as the secondary phase, and vapor as the third phase. PISO (Pressure implicit with

\begin{tabular}{|c|c|c|c|c|c|}
\hline boundary & phase & $\begin{array}{c}\text { density } \\
\rho\left(\mathrm{kg} / \mathrm{m}^{3}\right)\end{array}$ & $\begin{array}{l}\text { viscosity } \\
\eta(\mathrm{Pa} \times \mathrm{s})\end{array}$ & $\begin{array}{l}\text { velocity } \\
u(\mathrm{~m} / \mathrm{s})\end{array}$ & $\begin{array}{c}\text { temperature } \\
T(\mathrm{~K})\end{array}$ \\
\hline \multirow{2}{*}{$\begin{array}{c}\text { velocity } \\
\text { inlet }\end{array}$} & air & 1.225 & $1.7894 \times 10^{-5}$ & $u_{\text {in,air }}$ & 500 \\
\hline & water & 998.2 & 0.001003 & 0.3 & 373.15 \\
\hline \multirow{3}{*}{$\begin{array}{l}\text { pressure } \\
\text { outlet }\end{array}$} & air & 1.225 & $1.7894 \times 10^{-5}$ & & \\
\hline & water & 998.2 & 0.001003 & & 373.15 \\
\hline & vapor & 0.5542 & $1.34 \mathrm{e} \times 10^{-5}$ & & \\
\hline
\end{tabular}
splitting of operators) scheme is used to pressure-velocity coupling solution, and second order upwind is adopted to momentum, energy and swirl velocity; least squares cell based is adopted to gradient, and the first order implicit is adopted to transient formulation. The phase transition relationship between vapor and water is implemented by user defined function (UDF). At the standard atmospheric pressure, a phase transition between vapor and water occurs at the temperature $373.15 \mathrm{~K}$. The initial parameters for numerical computation can be seen in Table 1 .

Table 1 Initial parameters for numerical solution

\subsection{Grid independency tests}

The results of numerical solutions are affected by grid number used in the simulation. Mesh independence verification is necessary to avoid convergence problems caused by the inappropriate use of grids. To check the adequacy of the numerical scheme adopted in the present study and, the procedure has been tested at Fig. 2 by comparing $S h_{\mathrm{pj}}$. It was found that in No. 4 to 6 grid sizes the difference in $S h_{\mathrm{pj}}$ is always less than $0.19 \%$

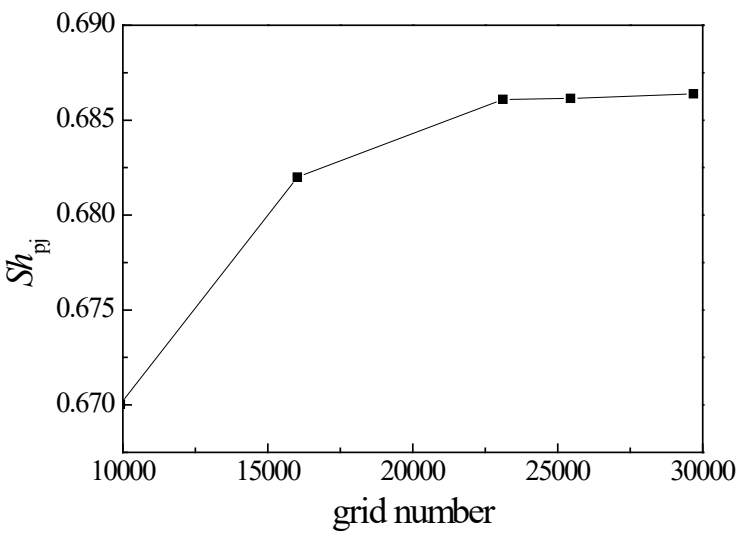

Fig. 2 mesh independence verification

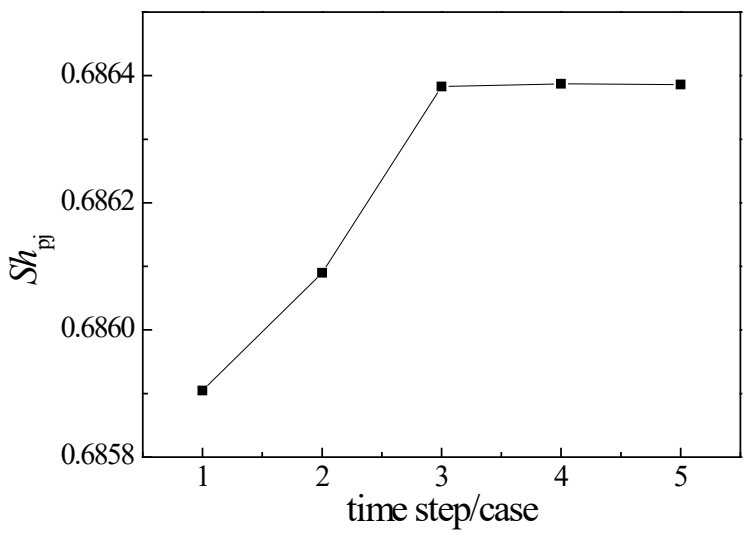

Fig. 3 time step independency test 
As shown in Fig.3, in order to assess the time step, five time steps are calculated, which are $0.0005 \mathrm{~s}, 0.001 \mathrm{~s}, 0.005 \mathrm{~s}, 0.01 \mathrm{~s}$ and $0.05 \mathrm{~s}$. When the time step is irrelevant, when the time step is $0.001 \mathrm{~s}$, the difference between the $S h_{\mathrm{pj}}$ of the time steps before and after the time step is less than $0.018 \%$, so it is more appropriate to use this time step for calculation.

\section{RESULTS AND DISCUSSION}

\subsection{Different effects from uniform and pulsating airflow}

Fig. 4 shows the mass flow rate as a function of evaporation time for both uniform $\left(u_{\text {in,air }}=3 \mathrm{~m} / \mathrm{s}\right)$ and pulsating airflow $\left(u_{0}=3 \mathrm{~m} / \mathrm{s}, A_{0}=1\right.$ $\mathrm{m} / \mathrm{s}, t_{0}=0.4 \mathrm{~s}$ )conditions. As time goes by, the trend of $S h$ for uniform airflow tends to be smooth, and $S h$ of pulsating airflow shows periodic changes over time; the period of $S h$ is consistent with the period of airflow velocity.

For uniform flow, the evaporation of liquid film on the vertical inner surface of the circular tube is affected by the air flow. In the early stage of evaporation, the vapor mass flow rate increases. Over time, a stable vapor concentration boundary layer is formed on the surface of liquid film, causing the stability of mass transfer. For pulsating airflow, the vapor concentration boundary layer at the liquid film boundary is periodically destroyed, the vapor is carried away by the pulsating airflow, and the velocity of new vapor formation on the liquid film surface is accelerated, so the mass transfer changes with the cycle.

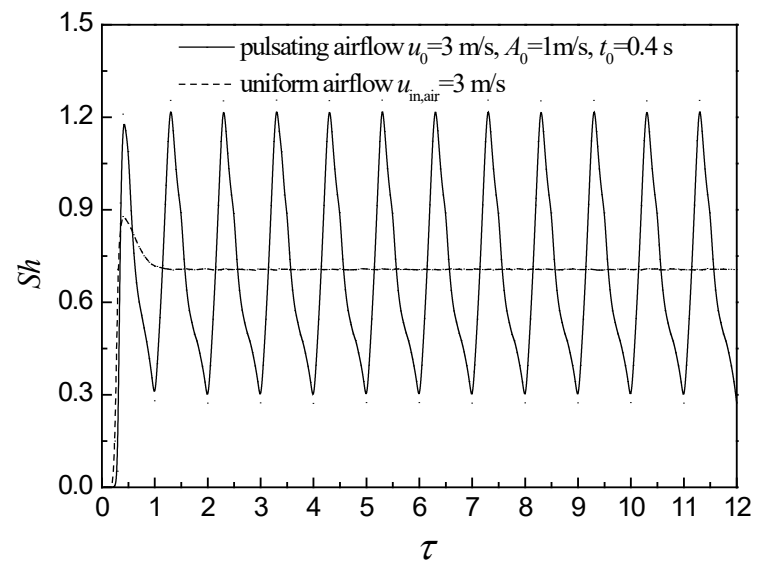

Fig. $4 S h$ vs. $\tau$

\subsection{Effect of relative amplitude on relative evaporation}

Fig. 5 shows the change of $S h_{\mathrm{pj}}$ under different relative amplitude $A$ when $u_{0}=7 \mathrm{~m} / \mathrm{s}$ and $W_{O}=9.3$. It can be seen from Fig. 5 that as the relative amplitude $A$ increases, $S h_{\mathrm{pj}}$ increases first and then decreases. When the relative amplitude $A=1 / 7$, the $S h_{\mathrm{pj}}$ reaches the maximum value, and the mass transfer effect of the pulsating airflow is relatively uniform. The airflow mass transfer effect is increased by $0.2 \%$. This is because, with the increase of the relative amplitude, the change range of the airflow velocity becomes larger, and the disturbance to the boundary layer of the liquid film surface is enhanced, thereby enhancing the mass transfer process. When the relative amplitude reaches a certain value, the pulsating air flow accelerates the flow of the liquid film, so that the thickness of the liquid film is reduced, and the evaporation rate of vapor decreases, so the mass transfer effect is weakened.

Pulsating airflow perturbs vapor concentration field on the water surface to a higher degree, and the factor of moisture mass transfer performance has been improved (Yang and He, 2004). As the relative amplitude increasing from 0 to $1 / 7$, the liquid film generates more vapor than the vapor generated by uniform airflow, because the pulsating airflow disturbs the boundary layer of vapor concentration, and then take the vapor away. As the relative amplitude increasing from
$1 / 7$, the trend of relative evaporation decreases rapidly. This is because as the relative amplitude increases, the disturbance to the boundary of liquid film and vapor enhances intensively. The maximum velocity of pulsating airflow increases due to the raise of relative amplitude. Therefore, the liquid film and vapor exit the channel quickly along with the high-velocity pulsating airflow, and the generation of vapor is too late. Hence, the liquid film is cutoff at the vertical inner channel.

Fig. 6 shows the change rule of $S h_{\mathrm{pj}}$ at different average velocity ( $A=0.5$ and $W o=9.3$ ). It can be seen from the figure that as the average pulsating airflow increases, $S h_{\mathrm{pj}}$ gradually increases. This is because, when the relative amplitude $A$ is a fixed value, as the average pulsating velocity increases, the amplitude of the airflow velocity becomes larger, the peak of the airflow velocity increases, and the disturbance to the boundary layer of the liquid membrane surface increases, thereby enhancing the mass transfer process.
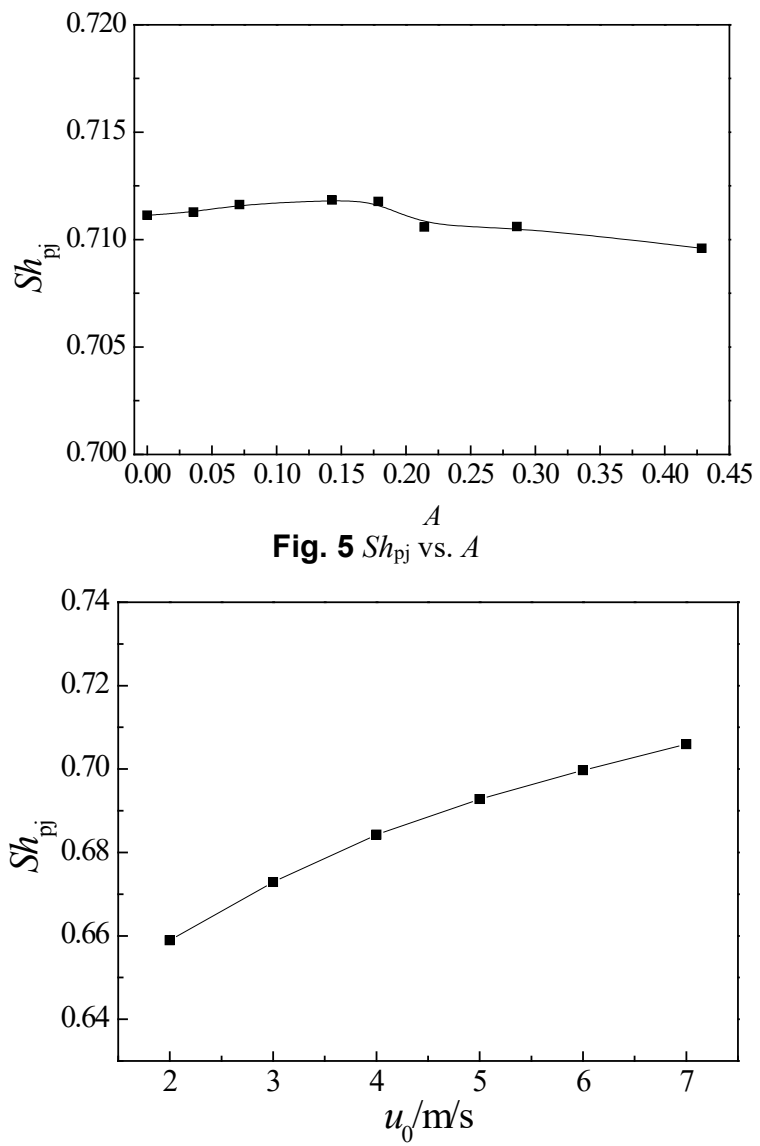

Fig. $6 S h_{\text {pj }}$ vs. $u_{0}(A=0.5)$

\subsection{Effect of pulsating airflow frequency on relative evaporation}

Fraenkel and Nogueira et al (1998) and Hommema and Temple et al (2002) have shown that the heat transfer performance of pulsating air flow under dry conditions is better. Fig.7 shows the change of $S h_{\mathrm{pj}}$ under different $W_{O}\left(u_{0}=7 \mathrm{~m} / \mathrm{s}\right.$ and $\left.A=1 / 7\right)$. It can be seen from the figure that when the $W o$ is less than 10 , as the $W o$ increases, $S h_{\mathrm{pj}}$ increases, and its mass transfer effect is improved by $0.3 \%$ relative to the uniform velocity airflow mass transfer effect. This is because the number of periodic changes of the pulsating airflow increases per unit time, and the number of times the vapor boundary layer on the liquid film surface is destroyed also increases. When the vapor boundary layer is destroyed, the vapor concentration gradient near the liquid film surface increases. The vapor diffuses in the direction of the gas stream with less concentration, and the convective mass transfer ability is enhanced. When $W_{O}>10$, as $W o$ increases, the $S h_{\mathrm{pj}}$ decreases. This is because after the pulsating frequency of the airflow increases, 
the pulsating airflow period decreases, which makes the pulsating airflow's ability to perturb the liquid film boundary layer close, and the mass transfer effect becomes poor.

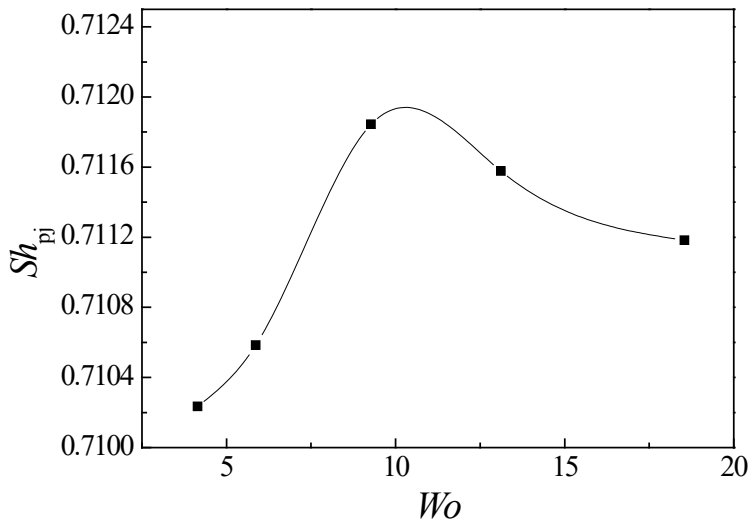

Fig. $7 S h$ vs. $W o$

\subsection{Effect of airflow velocity on relative evaporation}

Fig. 8 shows the effect of uniform airflow velocity on the mass transfer during falling film evaporation on a vertical channel. It can be seen from the figure that under the action of uniform airflow, $S h_{\mathrm{pj}}$ gradually increases as the airflow speed increases. This is because during the falling film evaporation process, as the airflow speed increases, the vapor on the surface of the liquid film is the speed of air flow is increased, and the mass transfer effect is enhanced.

As the uniform velocity increases, $S h_{\mathrm{pj}}$ decreases, thus the relative evaporation of vapor increases. Different airflow velocities perturb different degrees of disturbance to the liquid film. The relative evaporation increases as the airflow velocity increases, because the disturbance of airflow velocity destroys the boundary layer between liquid film and vapor. As the pulsating airflow taking vapor away, the liquid film generates vapor again. Airflow and liquid film are in direct contact. As the airflow velocity increases, the velocity of liquid film raises.

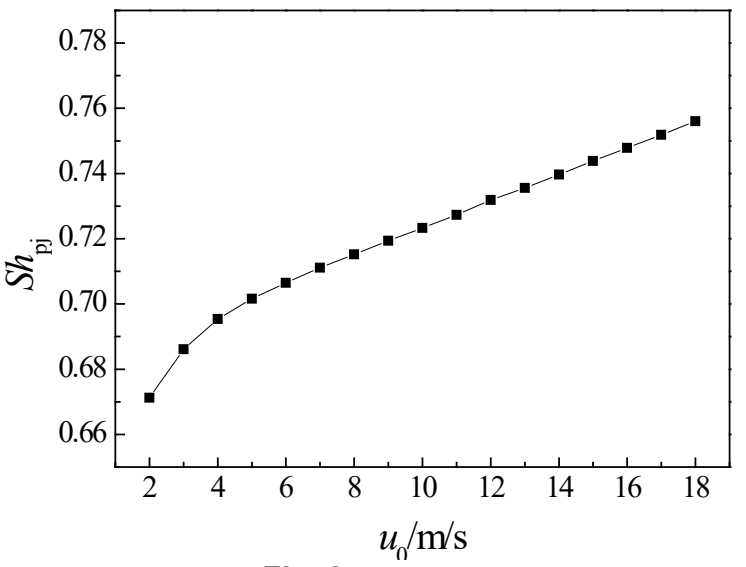

Fig. $8 S h_{\text {pj }}$ vs. $u_{0}$

\section{CONCLUSION}

In this work, the effects of serrated pulsating airflow on liquid film evaporation in a vertical channel were investigated and compared with uniform airflow at the same parameters. The following conclusions were drawn:

- The effect of pulsating velocity airflow on water evaporation was greater than that of uniform velocity airflow under the certain conditions. When the airflow was pulsating, the evaporation rate of water changed periodically, and the cycle of evaporation was the same as the pulsating airflow's cycle.
- The increase in pulsating amplitude promoted evaporation within a certain range. Compared with uniform velocity airflow, the relative evaporation increased by $0.3 \%$ due to the effect of pulsating. The increase in pulsating amplitude promoted evaporation. Compared with uniform velocity airflow, the relative evaporation increased by $0.2 \%$ by the effect of frequency. This was because pulsating airflow disturbed the boundary layer, and then took vapor away, which promoted to reproduce vapor.

- Compared with uniform velocity airflow, pulsating airflow can enhance the convective mass transfer effect of vertical flat falling film evaporation.

\section{ACKNOWLEDGEMENTS}

The authors would like to thank financial support from projects subsidized by special funds for industrial development of Shenzhen Dapeng New District (Grant No.KY20180113) and projects subsidized by Shenzhen Science and Technology Innovation Committee (Grant NO. JCYJ20170818111558146).

\section{NOMENCLATURE}

A pulsating relative amplitude

$A_{0} \quad$ inlet airflow pulsating amplitude $(\mathrm{m} / \mathrm{s})$

$C_{\mu} \quad$ viscosity constant

$C_{\mathrm{p}} \quad$ specific heat $(\mathrm{kJ} /(\mathrm{kg} \cdot \mathrm{K}))$

$D \quad$ diameter of physical model (m)

$g \quad$ gravitational acceleration $(\mathrm{N} / \mathrm{kg})$

$H \quad$ height of physical model (m)

$k \quad$ kinetic energy

$k_{1} \quad$ thermal conductivit $(\mathrm{W} /(\mathrm{m} \cdot \mathrm{K}))$

$K_{0} \quad$ characteristic coefficient of vapor in the air

$r \quad$ evaporation-condensation coefficient

$R \quad$ radius of physical model (m)

Sh Sherwood number

$S h_{\mathrm{pj}} \quad$ average Sherwood number

to evaporation time (s)

$T \quad$ system temperature (K)

$T_{\text {cons }} \quad$ normal temperature (K)

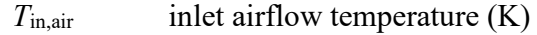

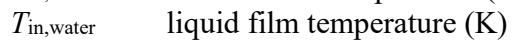

$T_{\mathrm{s}} \quad$ saturation temperature $(\mathrm{K})$

$u, v \quad$ velocity components in $\mathrm{x}, \mathrm{r}$ coordinate directions, respectively $(\mathrm{m} / \mathrm{s})$

$u_{0} \quad$ mean velocity of pulsating airflow $(\mathrm{m} / \mathrm{s})$

Wo Womersley number

Greek Symbols

$\delta \quad$ liquid film thickness (m)

$\varepsilon \quad$ turbulent dissipation rate

$\rho \quad$ density $\left(\mathrm{kg} / \mathrm{m}^{3}\right)$

$\alpha \quad$ volume fraction

$\eta \quad$ dynamic coefficient of viscosity $\left(\mathrm{N} \cdot \mathrm{s} / \mathrm{m}^{2}\right)$

$\eta_{\mathrm{t}} \quad$ turbulence coefficient of viscosity

$\tau \quad$ dimensionless time

Subscripts

a air

g mixture (air + vapor)

$\mathrm{v} \quad$ vapor

w water

\section{REFERENCES}

Chen, D.,2018, "Vortex characteristics and pressure pulsating analysis of Francis turbine based on RNG $k-\varepsilon$ and LES," Chinese Academic Journal Electronic Publishing House, 7. 
Choi, J.H and Yoon, D.J., 2019, "A stable operation method for membrane capacitive deionization systems without electrode reactions at high cell potentials," Water Research, 157: 167-174. https://doi.org/10.1016/j.watres.2019.03.083.

Douglas, J.F., Gasiorek, J.M. and Swaffield, J.A., 1995, "Fluid Mechanics", third ed, Longman Scientific \& Technical, Harlow.

Feng. Z.P., Guo. L.J. and Chen. X.J.,1998, "Study on transient heat transfer characteristics of horizontal spiral tube pressure drop pulsating transient," Chinese Journal of Nuclear Science and Engineering, 1998(01):6-12+2.

Fraenkel, S.L., Nogueira, J.A.H., Carvalho-Jr, J.A. and Costa F.S., 1998, "Heat transfer coefficients for drying in pulsating flows.," International Communications in Heat and Mass Transfer, 25(4): 471-480.

Gao, D., Morley, N.B. and Dhir, V., 2003, "Numerical simulation of wavy falling film flow using VOF method," Journal of Computational Physics, 192: 624-642. https://doi.org/10.1016/j. jcp.2003.07.013

Gao, C.K. and Ruan, G.L., 2015, "Seawater desalination technology and engineering," Chemical Industry Press.

Goltsman, A., Saushin, I., Mikheev, N.and Paereliy, A., 2019, "Generation of sinusoidal pulsating flows in the channels of experimental setups," Flow Measurement and Instrumentation, 2019; 66: 60-66. https://doi.org/10.1016/j.flowmeasinst.2019.02.006

Han, Z.Z., Wang, J. and Lan. X.P., 2010, "FLUENT: Fluid Engineering Simulation Calculation Examples and Applications," Second ed. Beijing Institute of Technology Press, 20-22.

Huang, R.F., Yang, T.F. and Lan, Y.K., 2010, "Pulsatile flows and wall-shear stresses in models simulating normal and stenosed aortic arches," Exp. Fluid, 48: 497-508.

https://doi.org/10.1007/s00348-009-0754-y

Kærn, M.R., Markussen, W.B., Meyer, K.E., Elmegaard, B. and Palm, B., 2018, "Experimental comparison and visualization of in-tube continuous and pulsating flow boiling," International Journal of Heat and Mass Transfer, 2018; 125: 229-242. https://doi.org/10.1016/j.ijheatmasstransfer.2018.04.060

Kihara. T., Obata. H. and Hirano. H., 2019, "Quantitative visualization of fluid mixing in slug flow for arbitrary wall-shaped microchannel using Shannon entropy," Chemical Engineering Science, 2019; 200: 225-235. https://doi.org/10.1016/j.ces.2019.02.007.

Lee, W.H.,1980, "A pressure iteration scheme for two-phase flow modeling," Washington, USA: Hemisphere Publishing.

Liu, X.D., 2001, "Spray Drying of Pulsating Flow Generated by a Pulse Combustor," Transactions of the Chinese Society for Agricultural Machinery, 32(1): 56-58. $\quad$ http://doi.org/10.3969/j.issn.1000$\underline{1298.2001 .01 .015}$

Li, G.N., Xiang, Z.X., Zheng, Y.Q. and Hu, G.L, 2012, "Heat transfer enhancement with a flat plane in laminar pulsating flow," CIESC Journal, 63(06): 1717-1722. http://doi.org/10.3969/j.issn.04381157.2012.06.009.

Li, P., Guo, D.Z.and Liu, R.R, 2019, "Mechanism analysis of heat transfer and flow structure of periodic pulsating nanofluids slot-jet impingement with different waveforms." Applied Thermal Engineering, 152: 937-945. https://doi.org/10.1016/j.applthermaleng.2019.01.086

Lim, L. and Lim, J.J., E.W.C., 2019, "Mixing and segregation behaviors of a binary mixture in a pulsating fluidized bed," Powder Technology, 345: 311-328. $\quad$ https://doi.org/10.1016/j.powtec. $\underline{2019.01 .026}$
M. Feddaoui, A. Mir, E. Belahmidi., 2003, “Cocurrent turbulent mixed convection heat and mass transfer in falling film of water inside a vertical heated tube," Heat Mass Transfer, 46: 3497-3509. https://doi.org/10.1016/S0017-9310(03)00129-7

Scott.E. Hommema, Keith.A. Temple, James.D. jones, Victor.W. Goldschmidt., 2002, "Heat transfer in condensing, pulsating flows," International Journal of Heat and Mass Transfer, 45(1): 57-65. https://doi.org/10.1016/S0017-9310(01)00132-6

Srivastava, A. and Dhiman, A., 2019, "Pulsatile flow and heat transfer of shear-thinning power-law fluids over a confined semi-circular cylinder," the European Physical Journal Plus, 134: 144. https://doi.org/10.1140/epjp/i2019-12481-9

Teng, M.X.W. and Lim, E. W.C, 2018., "Heat transfer from an immersed tube in a pulsating fluidized bed," Applied Thermal Engineering, 143: 326-339.

https://doi.org/10.1016/j.applthermaleng.2018.07.087

Tao, W.Q., 1988, "Numerical Heat Transfer," 2nd edition. Xi'an Jiaotong University Press. 347-353.

Vivekanand, S.V.B. and Raju1, V.R.K., 2019. "Effect of wall contact angle and carrier phase velocity on the flow physics of gas-liquid Taylor flows inside microchannels," Chemical Papers, 73: 1173-1188. https://doi.org/10.1007/s11696-018-0668-3.

Wang, S.C., Zhou, Q. and Wang, Z., 2003, "Development trend of seawater desalination and reverse osmosis technology," Membrane Science and Technology, 04: 162-165, 171. https://doi.org/10.3969/j.issn.1007-8924.2003.04.030

Wu, F. and Wang, Q.W., 2007, "Numerical simulation on heat transfer enhancement inside internally longitudinal protuberant finned tube under pulsating flow," Proceedings of the CSEE, 27(35): 108-112. https://doi.org/10.3321/j.issn:0258-8013.2007.35.020.

Xie, L.X., Li, P.L. and Wang, S.C., 2003, "Review of seawater desalination technology and various desalination methods," Chemical Industry and Engineering Process, 22(10): 1081-1084.

https://doi.org/10.3321/j.issn:1000-6613.2003.10.011

Yakhot, V. and Orszag, S.A., 1986, "Renormalization group analysis of turbulence," I. basic theory. Journal of Scientific Computing, 1: 3-51.

Yang, W.W., He, Y.L. and Tao, W.Q., 2004, "Numerical study on enhancing mass transfer in grooved channel by pulsating flow," Journal of Xi'an Jiaotong University, 2004; 38(11): 1119-1122. https://doi.org/10.3321/j.issn:0253-987X.2004.11.005

Yang, P., Zhang, Y., Wang, X.F. and Liu, Y.W., 2018, "Heat transfer measurement and flow regime visualization of two-phase pulsating flow in an evaporator," International Journal of Heat and Mass Transfer, 127: 1014-1024.

https://doi.org/10.1016/ j.ijheatmasstransfer.2018.08.065

Zhai, M., Dong, P., Wang, X.Y., Ding, W.L. and Xia, X.L., 2009, "Numerical Simulation of Turbulent Pulsating Flow and Heat Transfer in Tubes," Proceedings of the CSEE, 29(20): 85-91. https://doi.org/10.13334/j.0258-8013.pcsee.2009.20.013

Zhai, M., Wang, X.Y., Ge, T.Z., Zhang, Y., Dong, P., Wang, F., Liu, F.W. and Huang, Y.D., 2015, "Heat transfer in valveless Helmholtz pulse combustor straight and elbow tailpipes," International Journal of Heat and Mass Transfer, 2015; 91: 1018-1025. https://doi.org/10.1016/j.ijheatmasstransfer.08.052

Zhong, Y., Ling, C.M. and Xie, G.N., 2020, "Numerical simulation research on effects of pulsating air flow on liquid film evaporation at vertical plate," Applied mathematics and mechanics, 41(5). https://doi.org/10.21656/1000-0887.400386. 